\title{
SEISMIC BEHAVIOR OF CONCRETE SHEAR WALL - FRAMES - STRUCTURAL SYSTEMS SUBJECTED TO EARTHQUAKE LOADS
}

\section{Fadwa Issa}

PHD student Department of Structural Engineering Faculty of Civil

Engineering, Damascus University

e-mail:fadwa.issa650@gmial.com

Mohamad Nazih Alyagchi Eilouch

Professor

Department of Structural Engineering

Faculty of Civil Engineering

Damascus University, Yarmouk University

e-mailnazihayagchi@gmail.com
Abbas Tasnimi

Professor

Department of Structural Engineering

Faculty of Civil Engineering

Damascus University

e-mail tasnimi@gmail.com

(Received May 9,2011 Accepted June 22, 2011)

In most designing cases, design engineers assign shear walls the total seismic loads while the frames (columns and beams) take the gravity loads. This procedure imposes additional seismic loads on the buildings; moreover the Syrian Code requires the application of the requirements related to seismic resistance on the frame elements (columns, beams and joints). This design procedure raises two basic issues. The first is the complete elimination of the frame effect on shear walls behavior regarding the internal forces and deformations. The second is the effect of the shear walls on the moment resisting frames behavior. In this study, the mutual effect of each system on the other is called interaction.

These systems are being studied by formulating several mathematical models covering buildings with shear walls and frames that have different heights and walls stiffness, expanding over a range of high and low stiffness values relative to the total stiffness of the building. Linear static and dynamic analyses have been applied on these models to show the possible contribution of frames in the performance of the building in terms of internal forces and deformations. This study also focuses on the nonlinear behavior of shear wall-frame structural system by using nonlinear pushover analysis.

At the end of this study, the most important results and recommendations are summarized, especially the necessity of considering the interaction between frames system and shear walls system. Increasing structural system factor is recommended when seismic loads are calculated. This leads to a reduction in the seismic loads on buildings.

KEY WORDS: shear wall-frame systems, nonlinear pushover analysis. 


\title{
الأداء الزلزالي لنظم إنشائية بيتونية من إطار- حوائط قص معرضة لأحمال الزلازل
}

\author{
م. فدوى عيسى \\ طالبة دكتوراه في قسم الهندسة الإنثائية

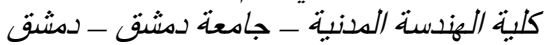 \\ e-mail:fadwa.issa650@gmail.com
}

\author{
أ.د.م عباس تسنيمي \\ أستاذ في قسم الهندسة الإنثائية

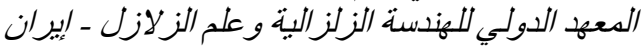 \\ e-mail tasnimi@gmail.com
}

\author{
أ.د.م محمد نزيه اليغشي إيلوش \\ أستاذ في قسم الهندسة الإنثائبة

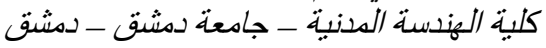

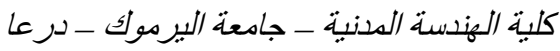 \\ e-mail: nazihayagchi@gmail.com
}

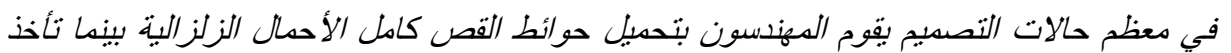

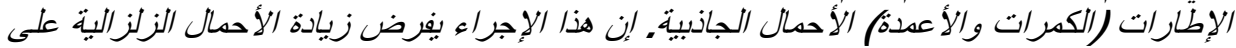

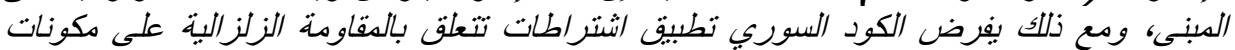

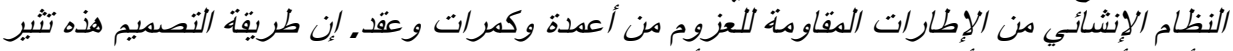

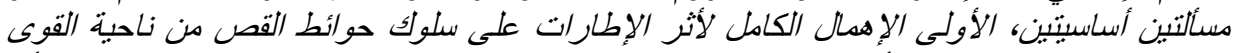

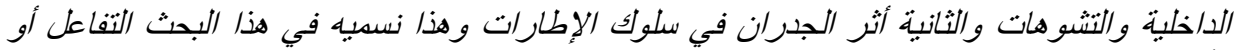

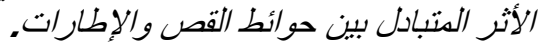

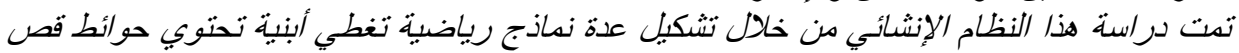

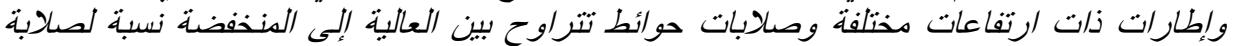

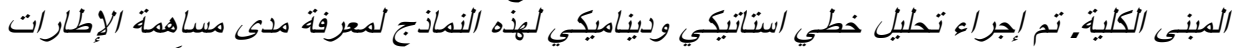

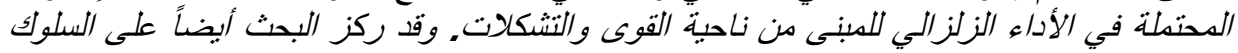

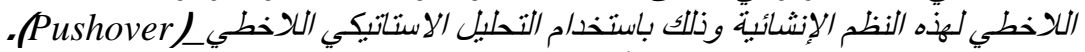

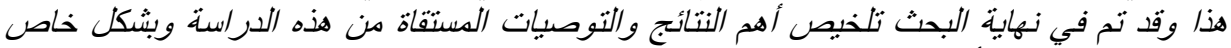

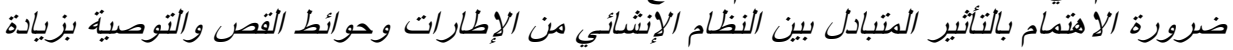

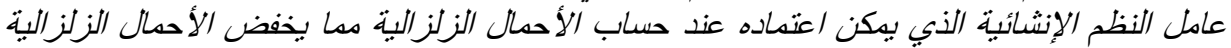
على المبانسي. كلمـاث مفتاحيه: نظام إنشائي إطار - حو ائط قص، تحليل استاتيكي لاخطي.

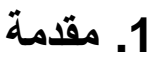

تتو اجد حو ائط القص و الإطار ات معاً في معظم الأبنية السكنية، وتسمى النظم الإنشائية التي تتم فيها مقاومة الأحمال

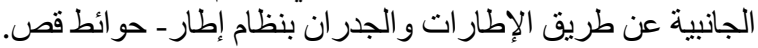

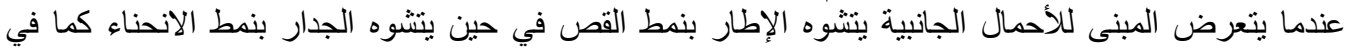

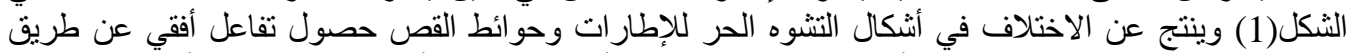

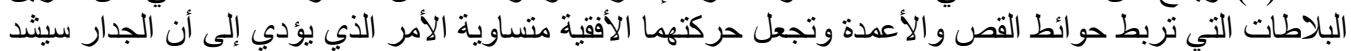

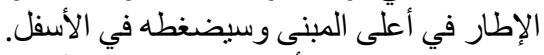

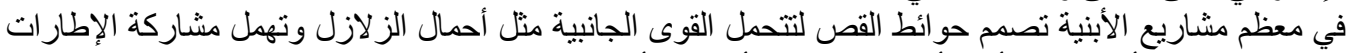

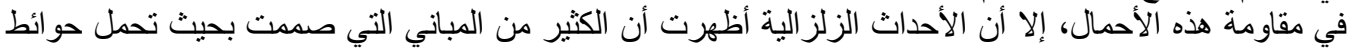

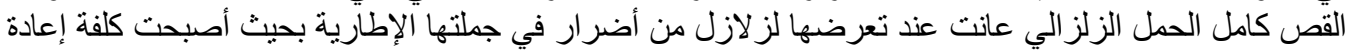

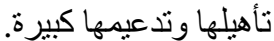

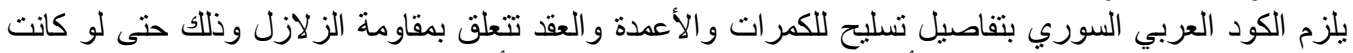

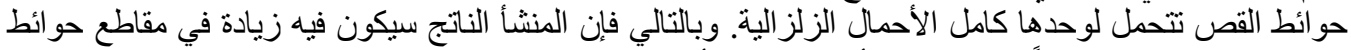
القص وتسليحهاو التي غالباً ما تتر افق مع أعمدة ظاهرة أول أو مخفية في نهاياتها. 

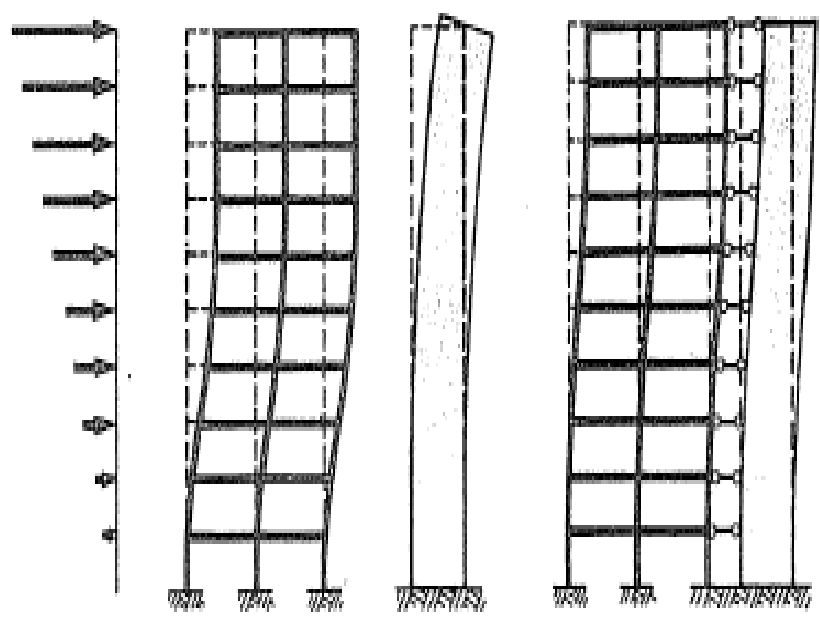

[4]

الثكل(1): شكل التشوه لكل من مكونات جمل إطار - جدار قص

\section{2. هدف البحث}

يهدف هذا البحث إلى دراسة سلوك جمل إطار - حو ائط قص لمباني سكنية وإظهار ميزات هذه النظم الإنشائية في كي

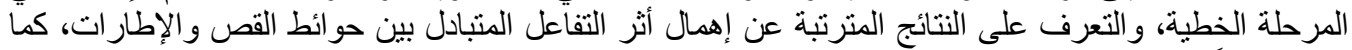
يهدف أيضاً إلى در اسة سلوك هذه النظم الإنشائية في المرحلة اللاخطية.

\section{3. مراجعة تاريخية للأبحاث السابقة}

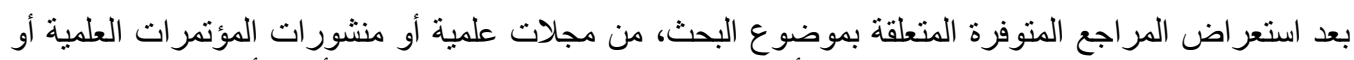

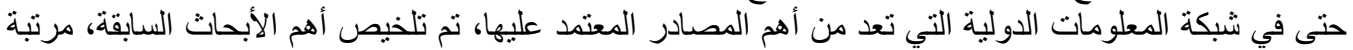
وفق تاريخ النشر:

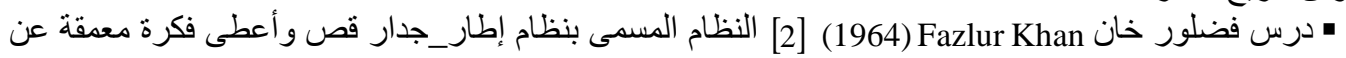

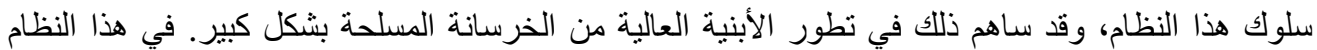

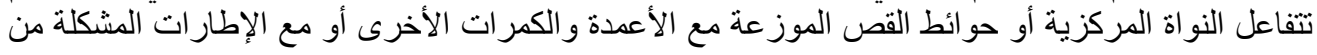

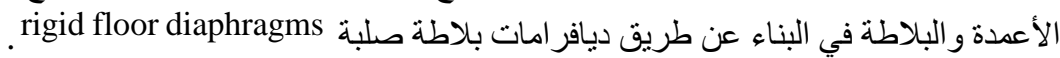

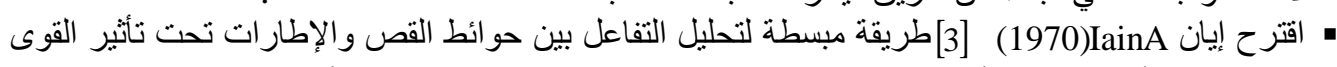

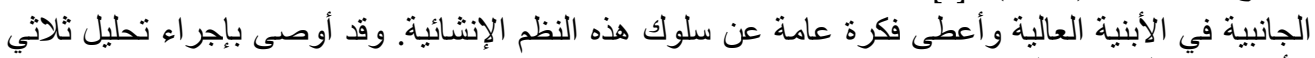
الأبعاد في حال وجود الانبه التواء و (Torsion).

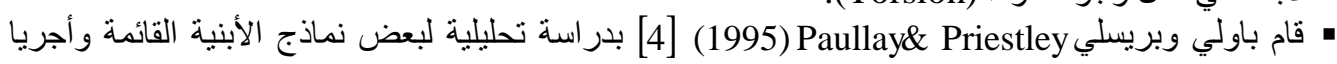

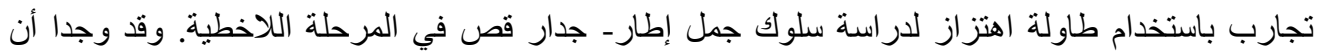

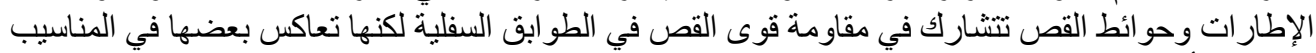

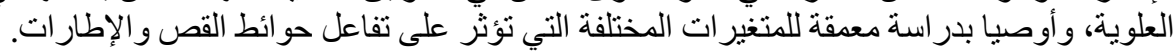

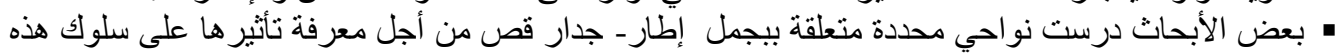

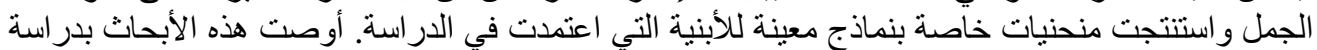

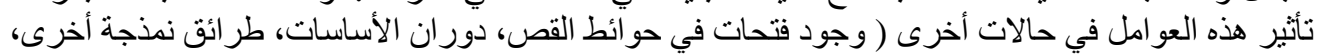

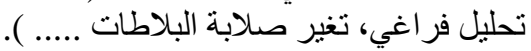

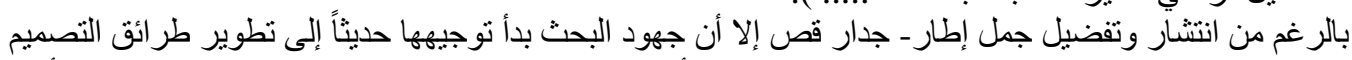

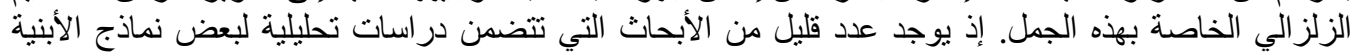


القائمة إضافة إلى أعمال تجريبية باستخدام اختبارات طاولة الاهتزاز مشيرة إلى احتمال استجابة زلز الية لا خطية ممتازة.

\section{4. النماذج النهاسية المدروسة}

تم اختيار النماذج الهنسية بحيث تغطي شر ائح مختلفة من المباني من حيث عدد الطوابق وبالتالي أدوار الاهتزاز

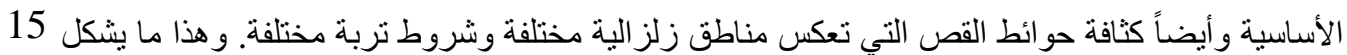

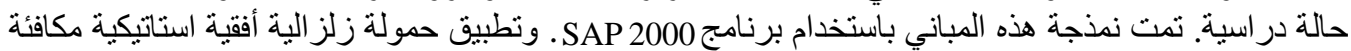

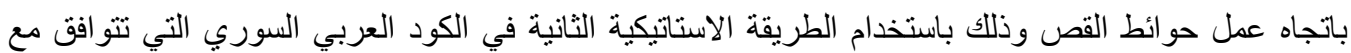

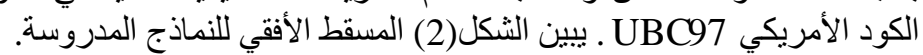

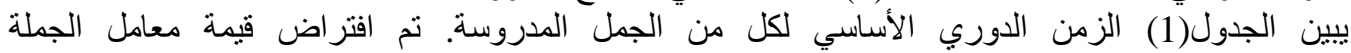

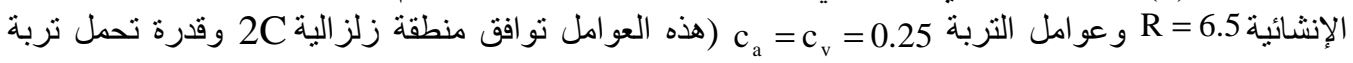

.$\left(\sigma \geq 3 \mathrm{~kg} / \mathrm{cm}^{2}\right.$

الجدول(1): الدور الأساسي (sec) للنماذج المدروسة باتجاه جدران القص

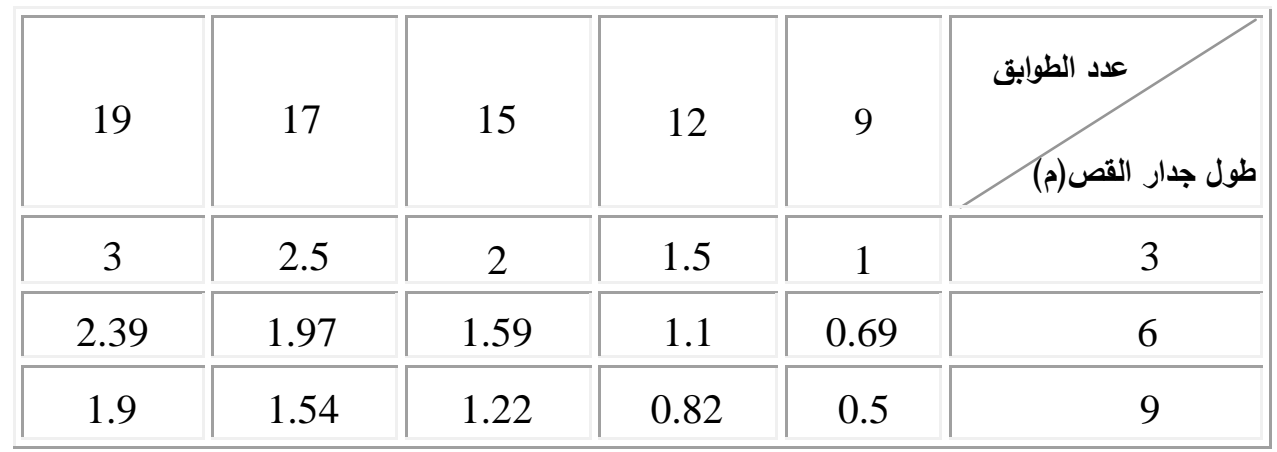

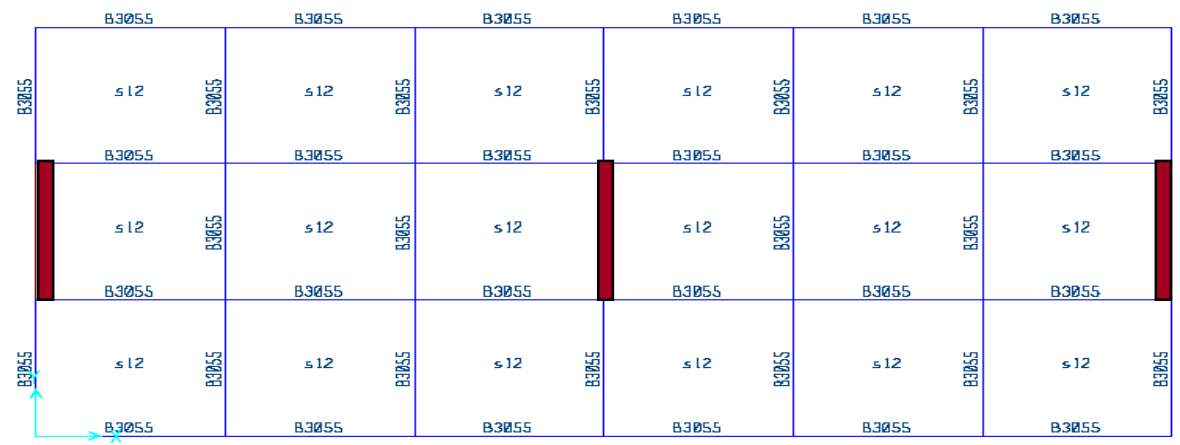

الثكل(2): المسقط الأفقي للنماذج المدروسة.

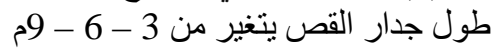

\section{5. أدوات البحث}

م برنامج SAP2000 - V9.1 استخدم للتحليل الاستاتيكي الخطي. م برنامج IDARC - V6 للتحليل الاستاتيكي اللاخطي والديناميكي اللاخطي، والذي طور في 


\section{جامعة Buffalo في نيويورك، إصدار 2006.

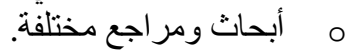

\section{6. دراسة سلوك جمل إطار- جدار ومميزات هذه الجمل في المرحلة الخطية}

\section{6. دراسة سلوك جمل إطار- جدار باستخدام تحليل استاتيكي خطي}

تمت دراسة النماذج المعتمدة في حالتين بهدف دراسة النتائج المترتبة على إهمال التفاعل المتبادل بين حوائط القص و الإطار ات على المقاومة التزلز الية، الحالتين هما:

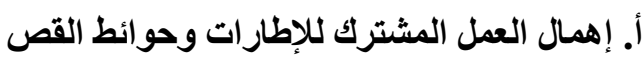

من أجل كافة النماذج فقد تم حساب حصة كل من حو ائط القص والإطار الفات من الأحمال الزلز الية المطبقة وفقاً لصلابتها مع إهمال مشاركة الإطار ات وبدون تأثئر العمل المشترك.

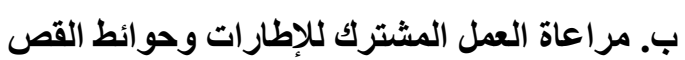

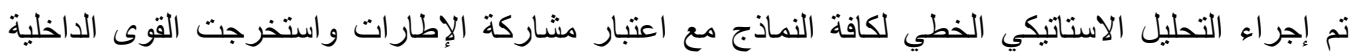

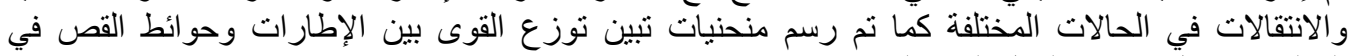
الحالتين: إهمال/مر اعاة العمل المشترك العات
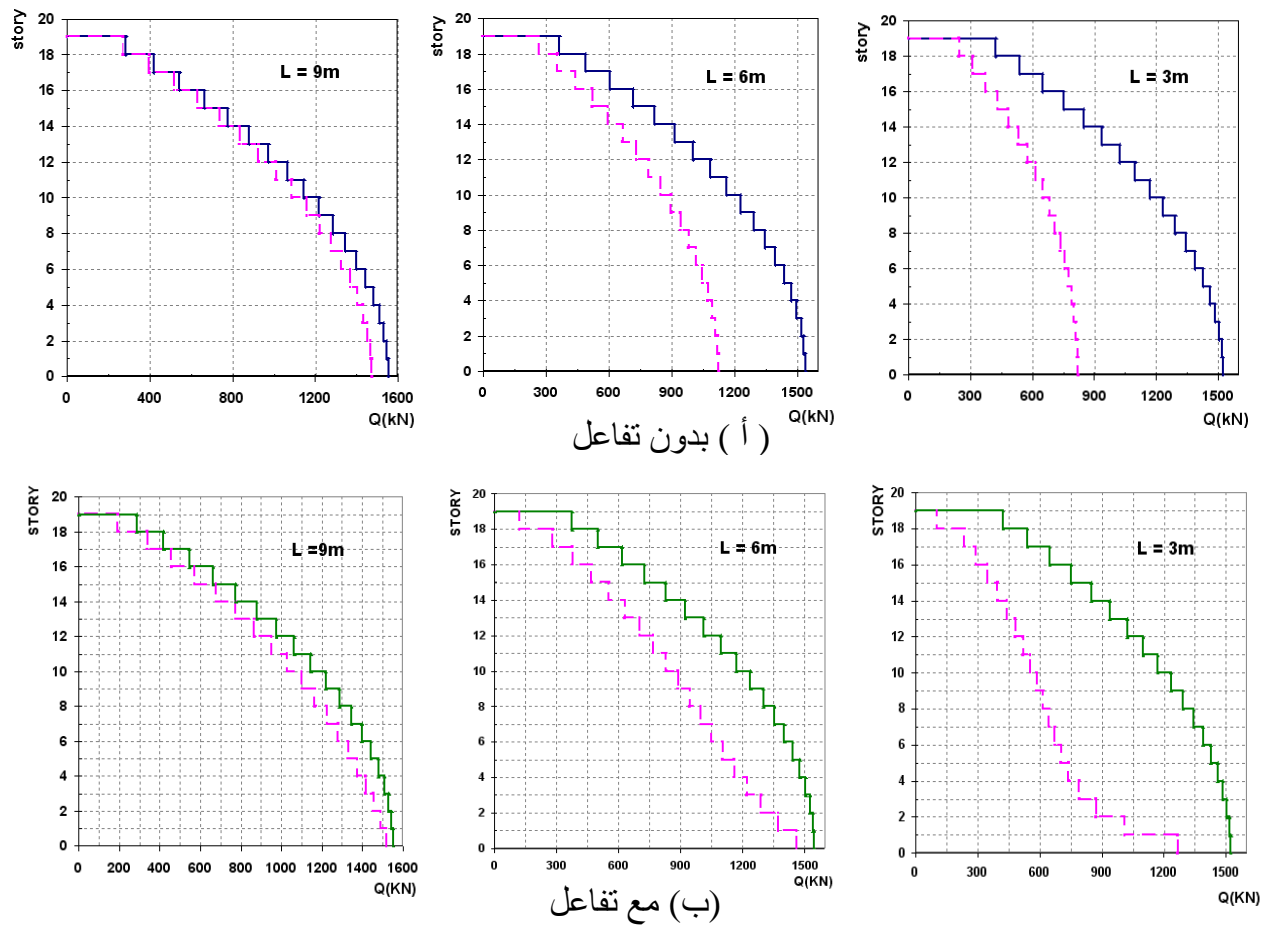

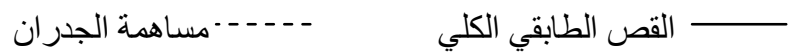

$$
\begin{aligned}
& \text { الثكل(3): توزع قوى القص الطابقية بين الجدران و الإطارات }
\end{aligned}
$$

ييين الثكل(3) مقارنة توزع قوى القص الطابقي بين حوائط القص و الإطارات في الحالتين: مع/بدون تفاعل. وفيها نجذ:

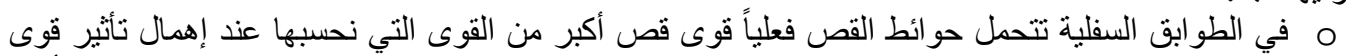

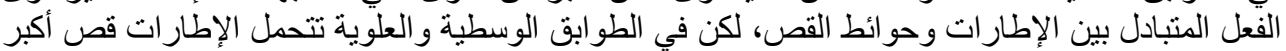


من القص الدحسوب عند إهمال أثر الفعل المتبادل.

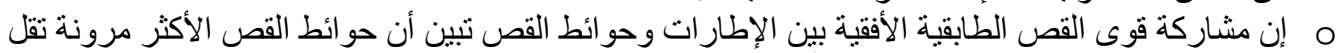

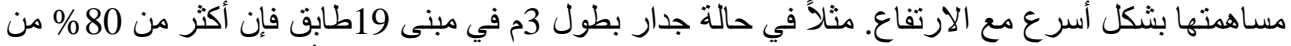

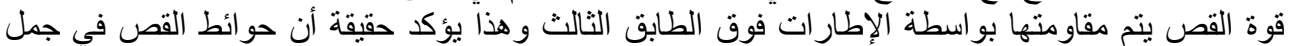

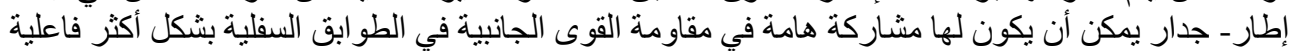

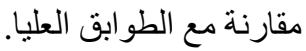
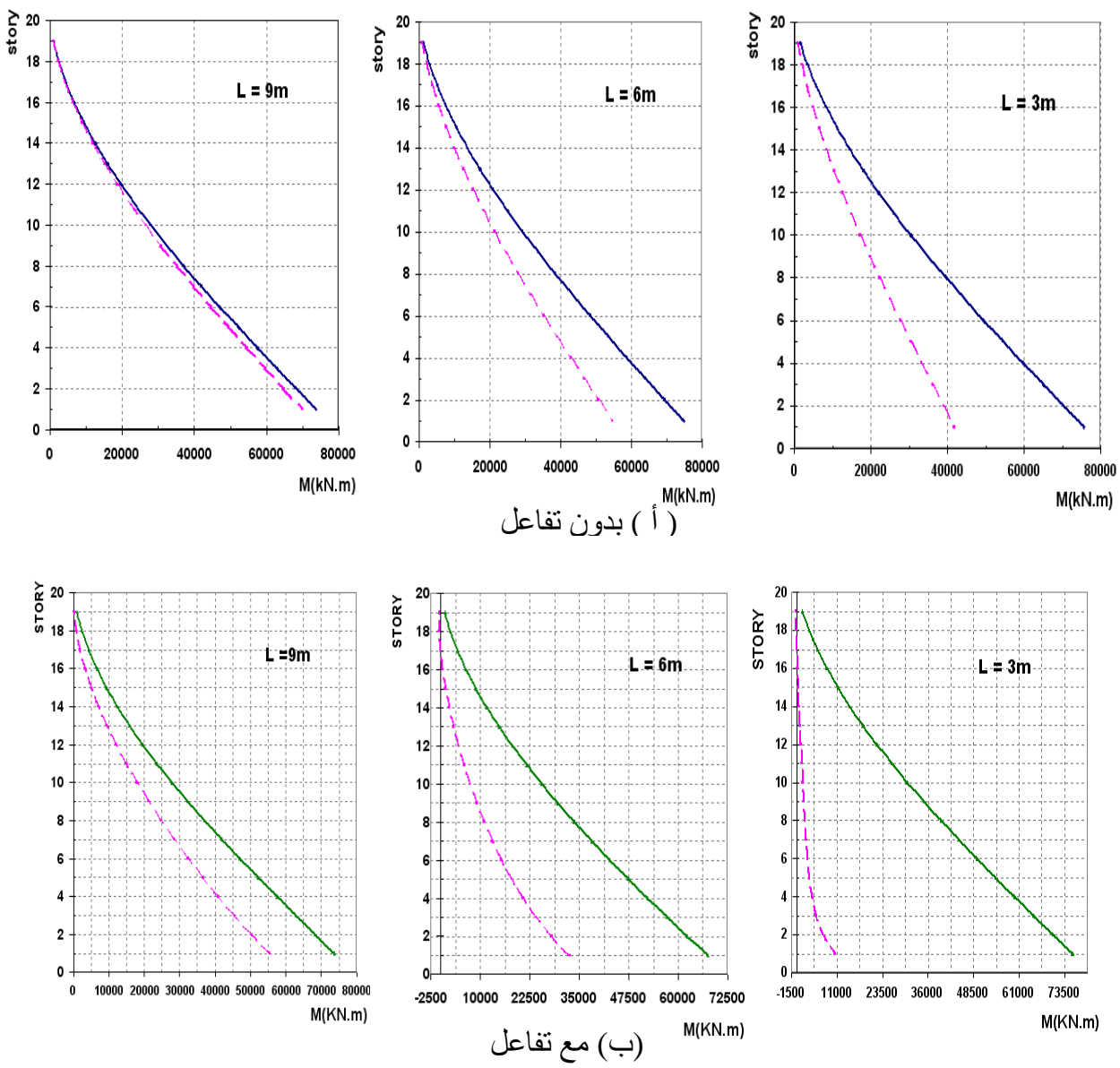

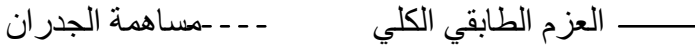

$$
\begin{aligned}
& \text { الثكل(4): توزع العزم الطابقي بين الجدران والإطارات }
\end{aligned}
$$

كما يبين الثكل(4) مقارنة توزع العزم الطابقي بين حوائط القص والإطارات في الحالتين: مع/بدون تفاعل.

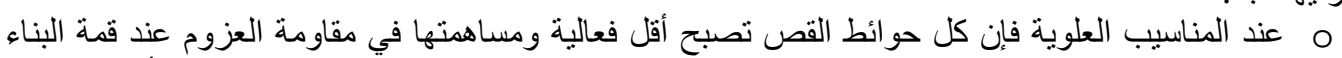

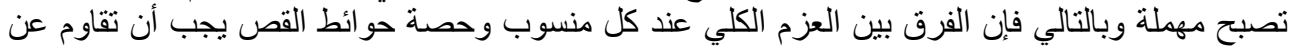

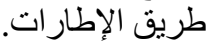
م بسبب تنافر التشوهات للمكونات المستقلة في الطوابق العليا تتعرض الإطارات لعزوم الكبر الكبر من العزم

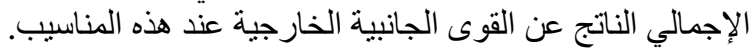
م إن مساهمة حوائط القص في مقاومة القوى الجانبية في جمل إطار - جدار تتغير غالباً بشكل سريع على ارتفاع 

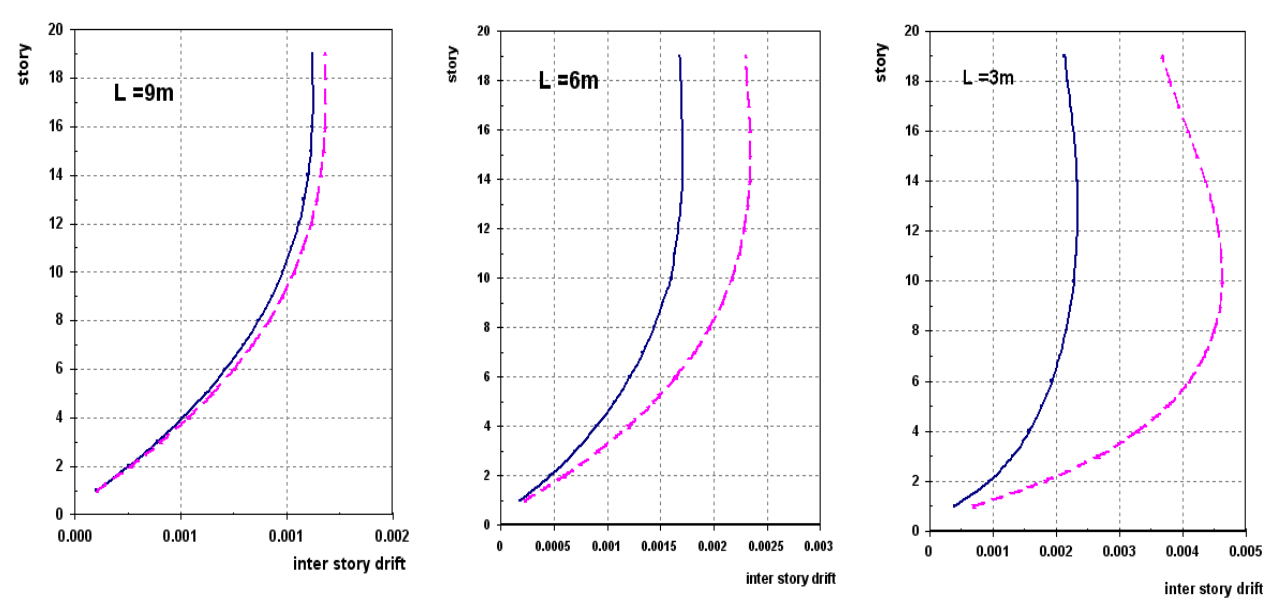

$$
\text { جدران + إطارات }
$$

الثكل(5): مقارنة الإزاحة الطابقية النسبية في الحالتين: مع/بدون تشغيل الإطارات

يظهر الثكل(5) تغير الإزاحة الطابقية النسبية مع الارتفاع في الحالتين: مع/بدون تشغيل الإطارات. وفيه نجد:

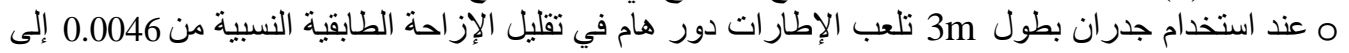

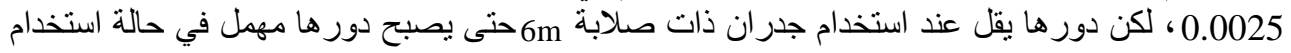
جدران بطول 9m حيث يسيطر العمل الجداري على سلوك جملة إطار - جدار قص.

\section{6. دراسة سلوك جمل إطار - جدار قص باستخدام تحليل ديناميكي خطي}

استخدم برناهج SAP2000 لإجراء تحليل ديناميكي خطي (Linear Time History Analysis ) للنماذج

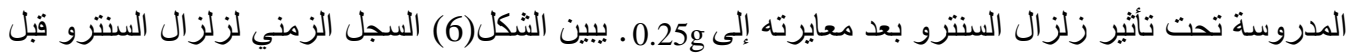
$[M],\{\ddot{U}\}+[C],\{\dot{U}\}+[K]:\{U\}=-[M]\left[\{\} \cdot \ddot{Y}_{g}\right.$ معايرته. تعطى المعادلة العامة للحركة بالعلاقة :

حيث [M] : مصفوفة الكتلة للمبنى.[C] : مصفوفة التخامد للمبنى.

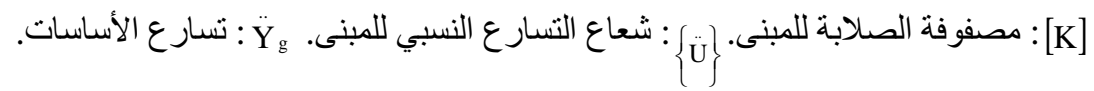

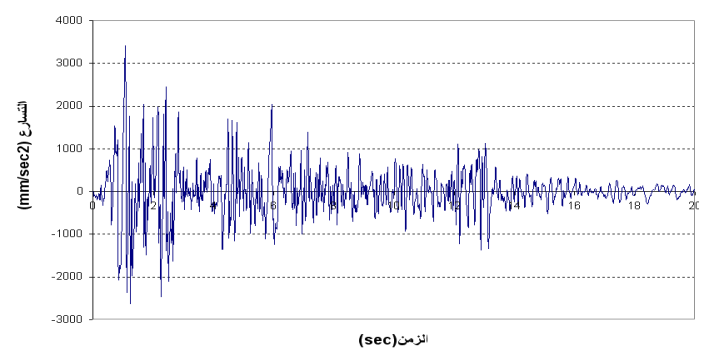

الثكل(6): السجل الزمني لزلزال السنترو قبل المعايرة

يبين الثكل(7) القص الطابقي الأعظمي الناتج من تحليل ديناميكي خطي تحت نأثر زلز ال السنترو، بمقارنة هذا الثكل مع الثكل(3) الذي يبين توز الأقعى القص الناتجة من تحليل استاتيكي نجد: 
م حوائط القص في جمل إطار- جدار يمكن أن يكون لها مشاركة هامة في مقاومة القوى الجانبية في الطوابق

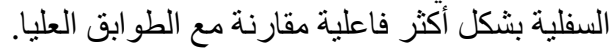

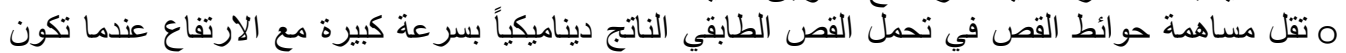

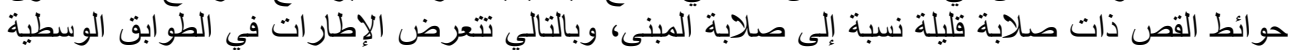

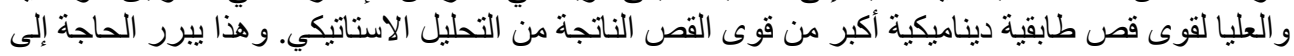

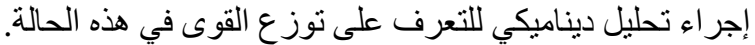
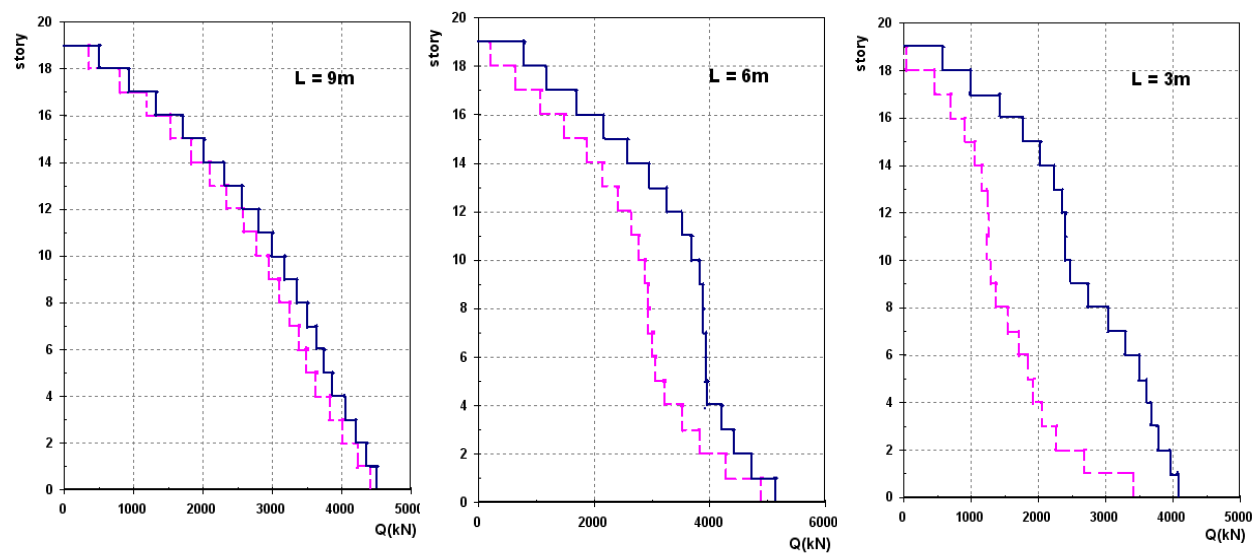

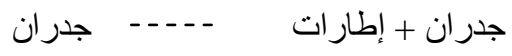

الثكل(7): القص الطابقي الأعظمي الناتج من تحليل ديناميكي خطي تحت تأثر زلزال السنترو المعاير إلى جلى

$$
0.25 g
$$

يبين الشكل(8) العزوم الطابقية الأعظمية الناتجة من تحليل ديناميكي خطي تحت نأثر زلز ال السنترو، بمقارنة هذا

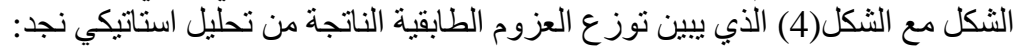

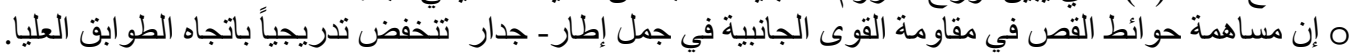

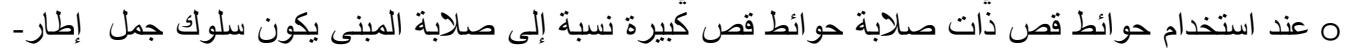

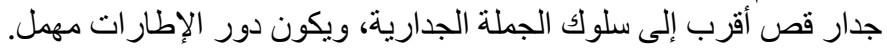
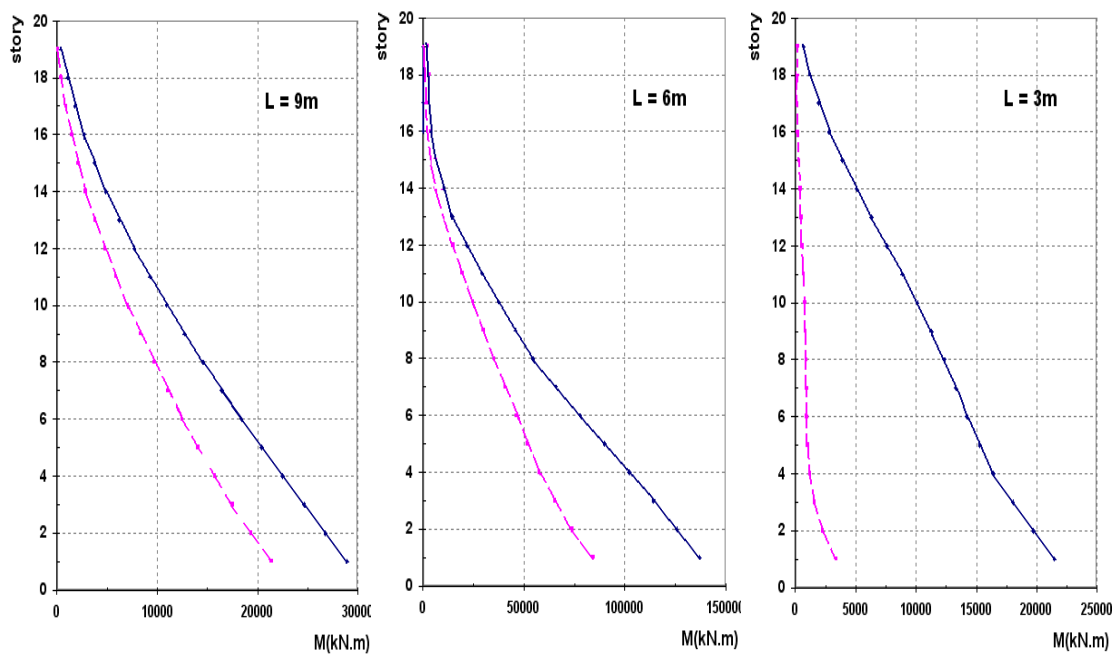

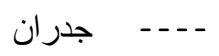$$
\text { جـدان + إطار ات }
$$

الشكل(8): العزوم الطابقية الأعظمية الناتجة من تحليل ديناميكي خطي تحت تأثر زلز ال

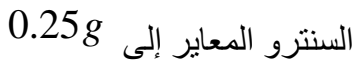




\section{7.دراسة سلوك جمل إطار- جدار قص وإظهار مميزات هذه الجمل في - إذبات

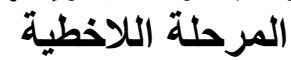

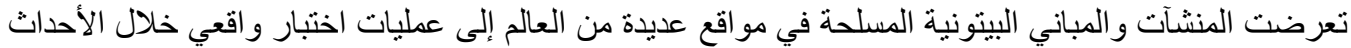

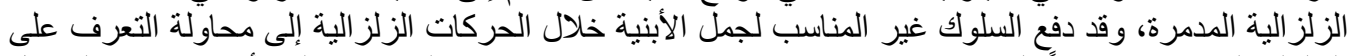

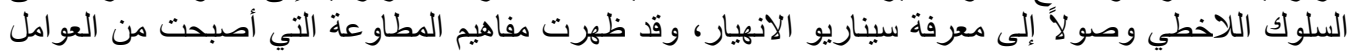

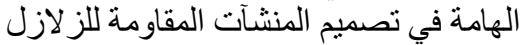

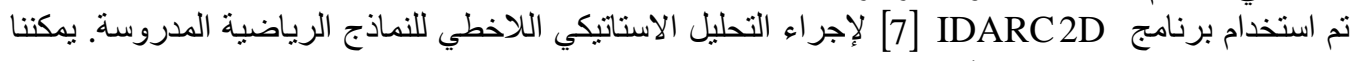

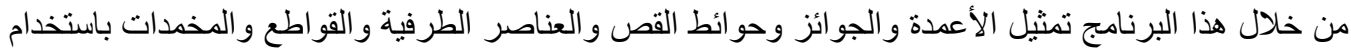

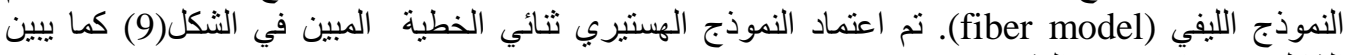
الشكل(10) بار امنر ات التشوه.

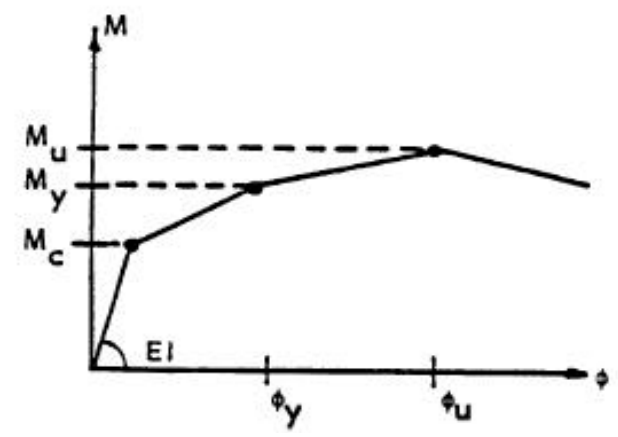

الشكل(10) : بار امتر ات التشوه [7]

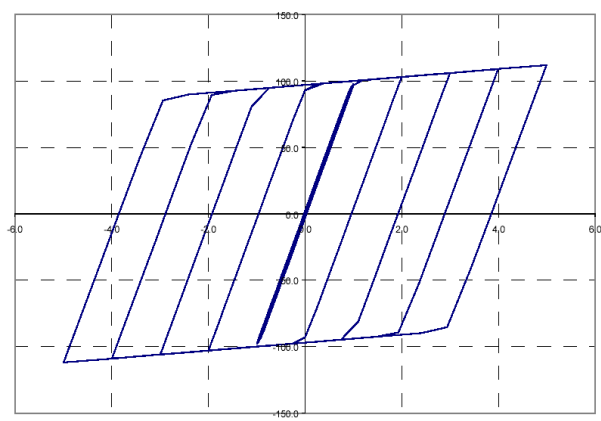

الثكل(9) : نموذج عن السلوك الثنائي [7]

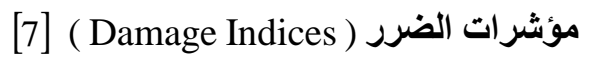

إن الغاية من مؤشرات الضرر هي تقييم استجابة المنشآت. وتحسب مؤشرات الضرر في البرنامج على مستوى

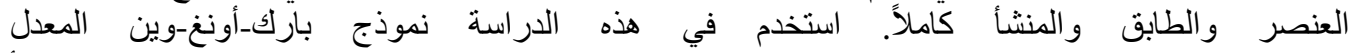
لحساب مؤشرات الضرر على مستوى العنصر و الطابق و المنشأ (Modified PARK_ANG_WEN Model) كاملاً. تعطى قيمة مؤشر بارك للضرر من أجل عنصر إنشائي بالعلاقة التالية:

$\mathrm{DI}=\frac{\theta_{\mathrm{m}}-\theta_{\mathrm{r}}}{\theta_{\mathrm{u}}-\theta_{\mathrm{r}}}+\frac{\beta}{\mathrm{M}_{\mathrm{y}} \cdot \theta_{\mathrm{u}}} \cdot \mathrm{E}_{\mathrm{h}}$

O ا $\theta_{m}$ O $\theta_{\text {r }}$ وقيمته 0.10 يتم حساب مؤشر الضرر علئه مستوى الطابق والمنشأ ككل باستخدام معاملات الوزن المتعلقة بالطاقة الهستيرية

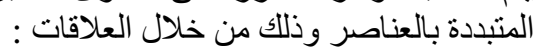

$$
\begin{aligned}
& \mathrm{DI}_{\text {story }}=\sum\left(\lambda_{\mathrm{i}}\right)_{\text {component }} \cdot\left(\mathrm{DI}_{\mathrm{i}}\right)_{\text {component }} ;\left(\lambda_{\mathrm{i}}\right)_{\text {component }}=\left(\frac{\mathrm{E}_{\mathrm{i}}}{\sum \mathrm{E}_{\mathrm{i}}}\right)_{\text {component }} \\
& \mathrm{DI}_{\text {overall }}=\sum\left(\lambda_{\mathrm{i}}\right)_{\text {story }} \cdot\left(\mathrm{DI}_{\mathrm{i}}\right)_{\text {story }} ;\left(\lambda_{\mathrm{i}}\right)_{\text {story }}=\left(\frac{\mathrm{E}_{\mathrm{i}}}{\sum \mathrm{E}_{\mathrm{i}}}\right)_{\text {story }}
\end{aligned}
$$

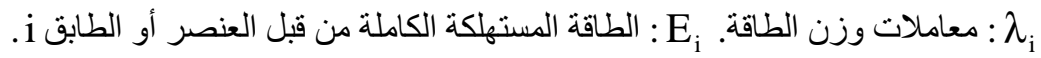


تم اختبار نموذج بارك ( Park )على تسعة أبنية من البيتون المسلح ومن خلال ظواهر الضرر المشاهدة نم اعتماد درجات الضرر الموضحة في الجدول التالي:

الجدول(2): درجة الضرر المرافقة لمؤشرات الضرر

\begin{tabular}{|c|c|c|c|}
\hline درجة الضرر & الظواهر المشاهدة & مؤشر الضرر & وضع المبنى \\
\hline انهيار & انهيار جزئي أو كلي للمبنى & $>1.0$ & انهيار كامل \\
\hline شديد & تصدع شديد في البيتون - تكثف لحديد تسليح & $0.4-1.0$ & ل غلإِصلاح قابل \\
\hline متوسط & شقوق كبيرة زائدة - تفلق البيتون في العناصر & $<0.4$ & قابل للإصلاح \\
\hline ققليل & شقوق صغيرة ـ تصدعات جزئية في الأعمدة & & غير متضرر \\
\hline بسيط بط & حدوث تشققات غير مستمرة & & غير متضرر \\
\hline
\end{tabular}

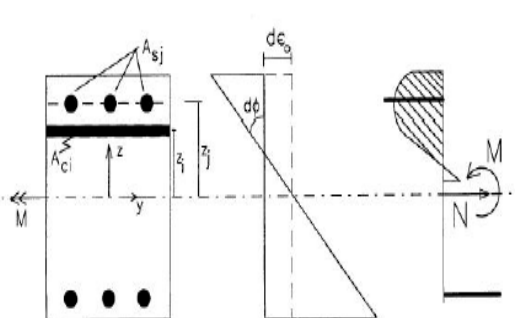

الثكل(11) : تفصيلة المقطع المدروس من

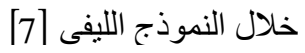

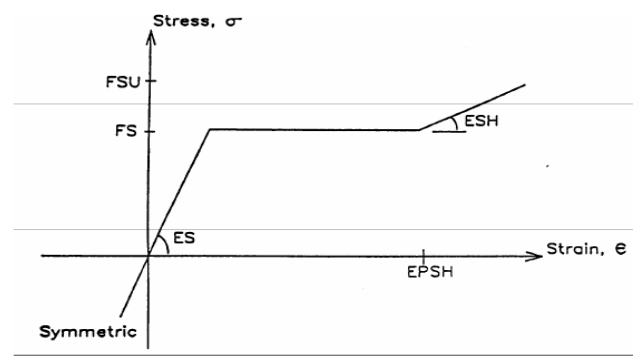

الثكل(12) : مخطط الإجهاد_الانفعال لحديد

التسليح [7] : ملخط الإن

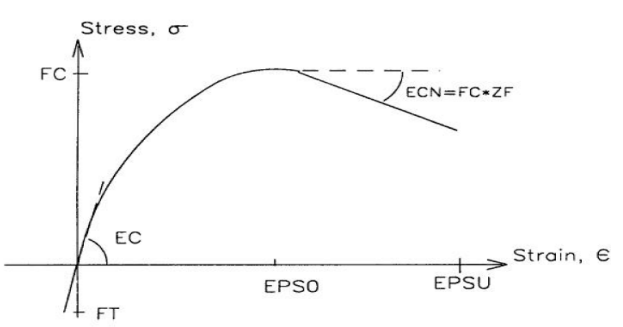

الثكل(14) : مخطط الإجهاد_الانفعال للبيتون غير

[7] [المطوق الإجاد 


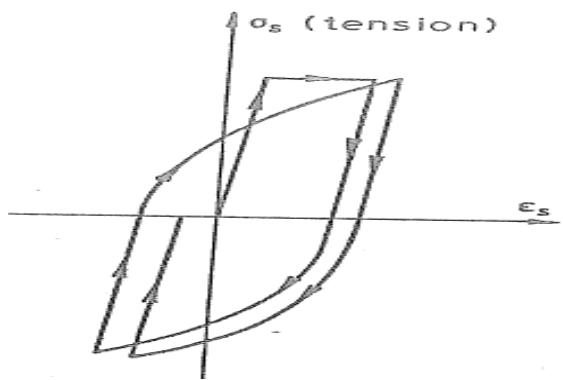

الثكل(15): مخطط الإجهاد ـ الانفعال لحديد معرض

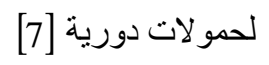

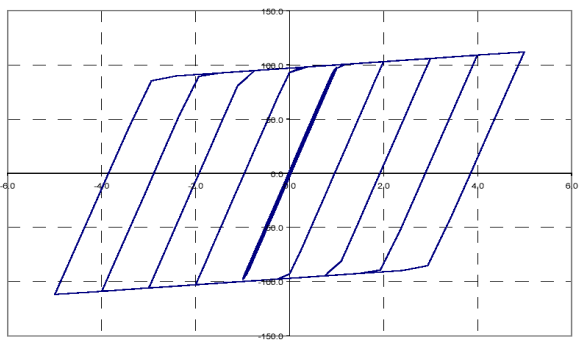

الثكل(16) : نموذج عن السلوك الثنائي [7]

يظهر الثكل(17) مقارنة العلاقة بين القص القاعدي النسبي ونسبة الاتنقال الأعظمي في أعلى المبنى إلى ارتفاعه

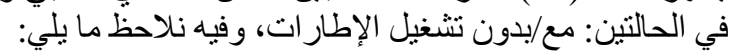
م تلعب الإطارات دور في التحمل في المرحلة اللاخطية حيث تلحمل حو الي

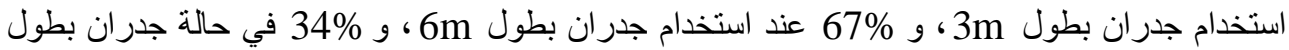

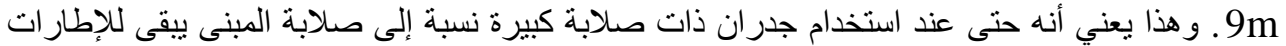
دور في التحمل في المرحلة اللاخطية.

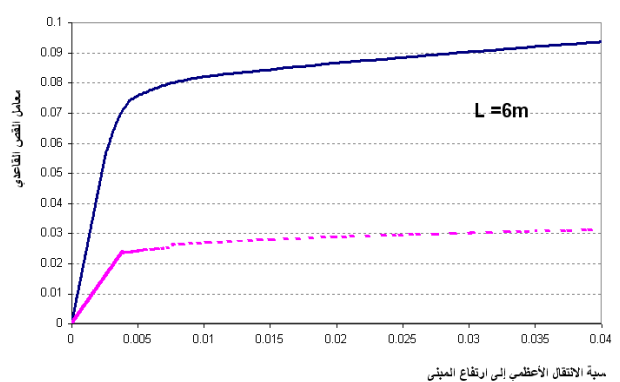

(ب)

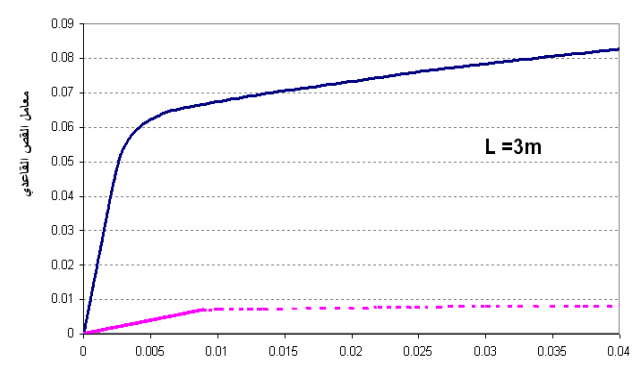

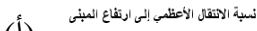

(l)

\section{تحليل ستاتيكي لا خطي}

Pushover Analysis

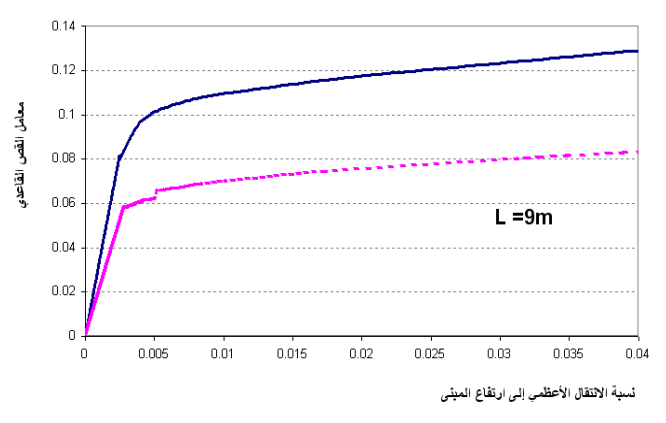

(ج)

$$
\text { جدران + إطارات }
$$

الثكل(17): مقارنة منحني العلاقة بين معامل القص القاعدي ونسبة الانتقال الأعظمي في

أعلى المبنى إلى ارتفاعه في الحالتين: مع/بدون تشغيل الإطارات 
يبين الثكل(18) العلاقة بين مساهمة حوائط القص وطولها من أجل عدة قيم للإزاحة الطابقية النسبية من أجل

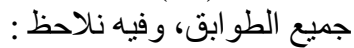
م تزداد مساهمة حو ائط القص بشكل واضط واضح مع زيادة صلابتها. فمن أجل الطابق الأول مثناً ومن أجل إزاحة

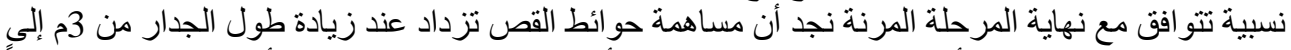

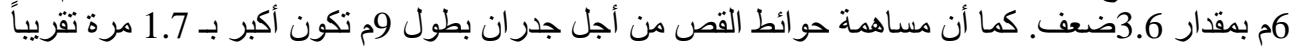

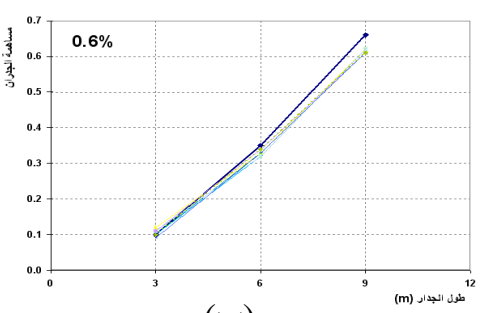

$(ب)$

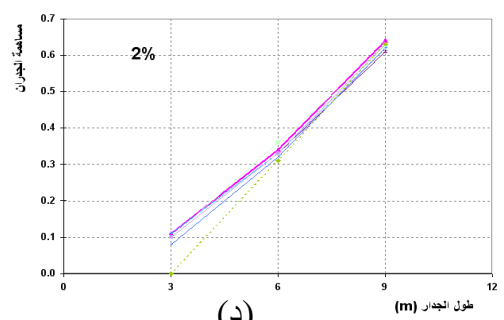

(د) من مساهمة جدر ان بطول 6م. ك.

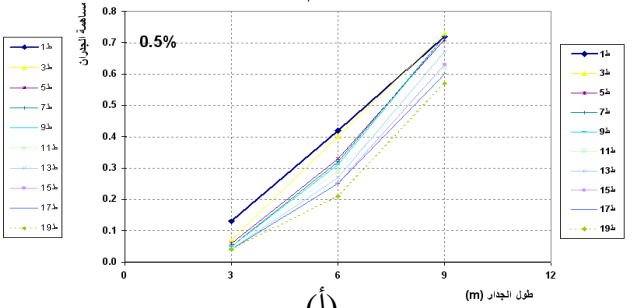

(ا)

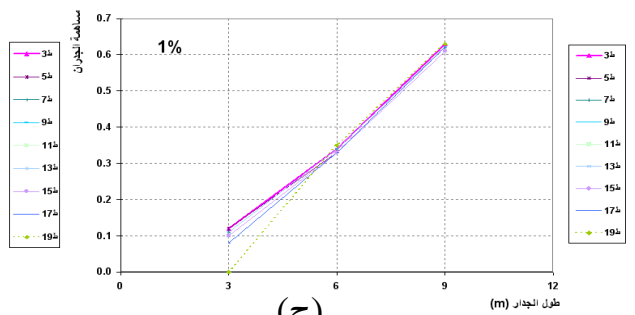

(ج)

الثكل(18): العلاقة بين مساهمة الجدران وطو لها من أجل عدة قيم للإز احة الطابقية النسبية يبين الثكل(19) تغير مساهمة حوائط القص عبر الارتفاع من أجل عدة قيم للإزاحة الطابقية النسبية، وفيه نلاحظ: م من أجل نسبة الانزياح الطابقي المو افقة لنهاية المرحلة المرنة ( 0.005 × ): تقل بشكل عام مساهمة حوائط

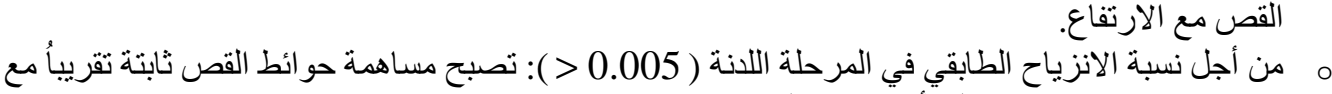

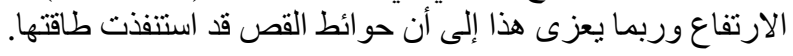

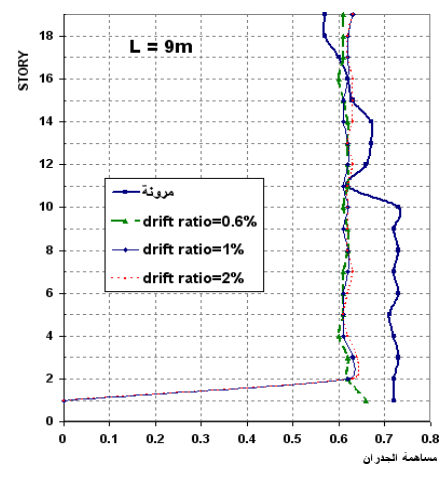

$(\rightarrow)$

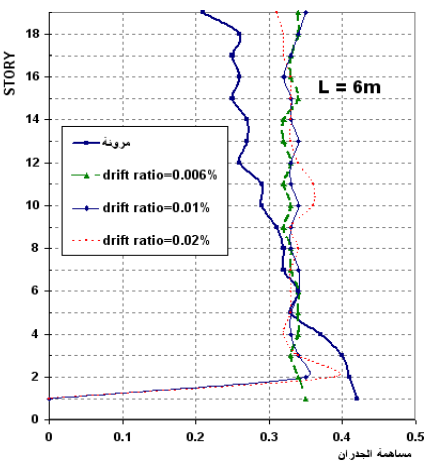

(山)

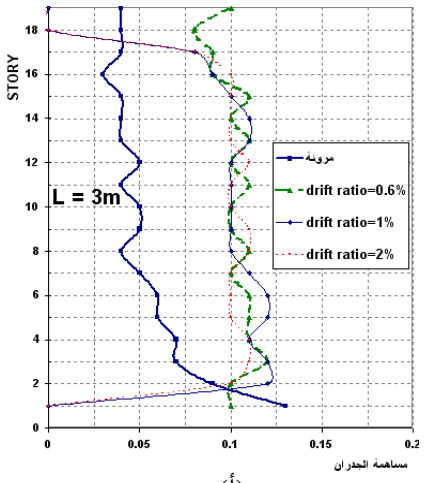

(أ)

الثكل(19): تغير مساهمة الجدران مع الارتفاع من أجل عدة قيم للإز احة الطابقية النسبية

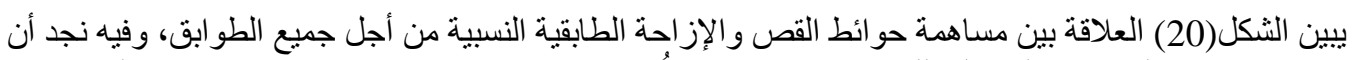

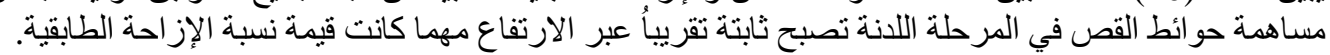



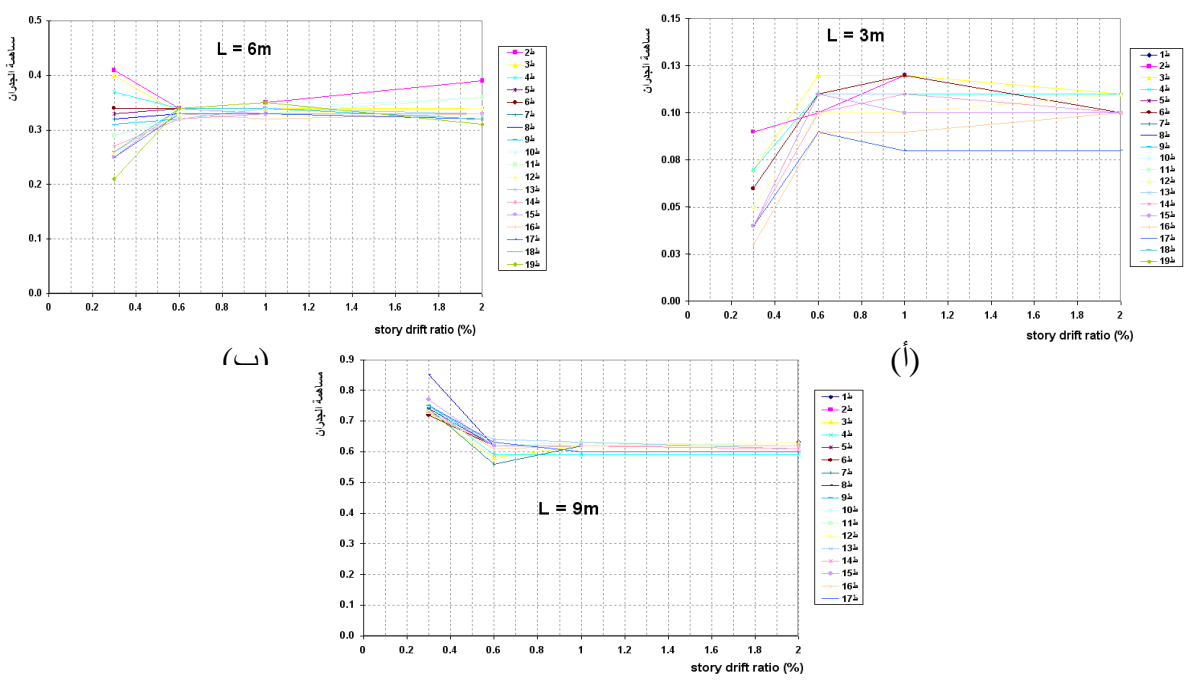

(l)

(ج)

الثكل(20): العلاقة بين مساهمة الجدران و الإزاحة الطابقية النسبية

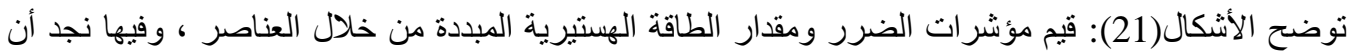
الإطارات تلعب دور هام في تقليل قيمة مؤشر الضرر للجدران عند الطن تعرض جمل إطار - جدار قص للز لازل.

\section{8. معامل الجملة الإنشائية في بعض الكودات العالمية والكود العربي السوري}

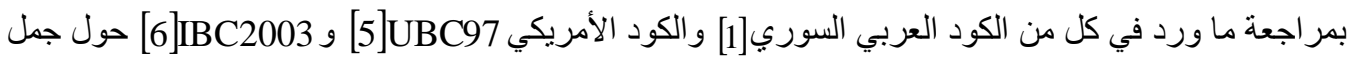

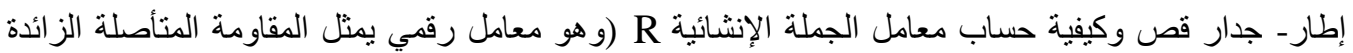
ومقدار الممطولية العامة للجملة المقاومة للقوى الأفقية) نجد مايلي:

م في الكودات الثلاثة نم نعريف جمل إطار- جدار قص (DualSystems) بأنها الجمل التي ينم فيها

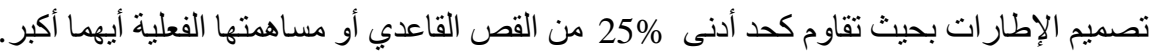

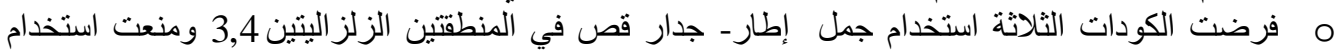

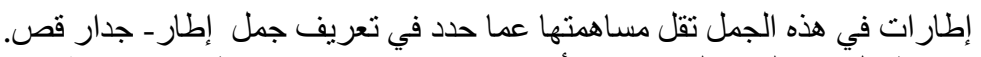

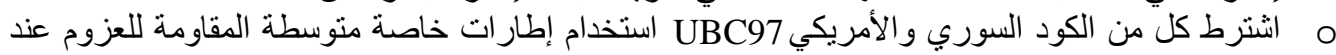

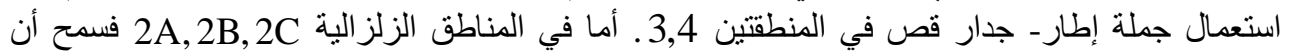
يكون الإطار متوسط المقاومة للعزم على الأقل.

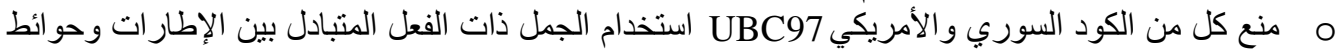

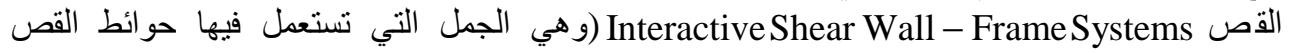
و الإطارات المصممة لمقاومة القوى الجانبية بنسبة قساو اتها النسبية مع الأخذ بالحسبان الفعل المنبادل بين حو ائط القص و الإطار ات على كافة المناسيب).

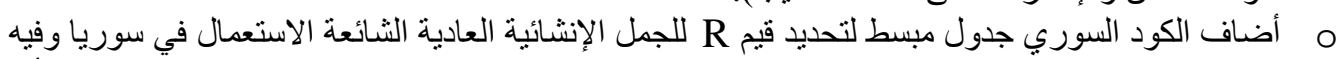

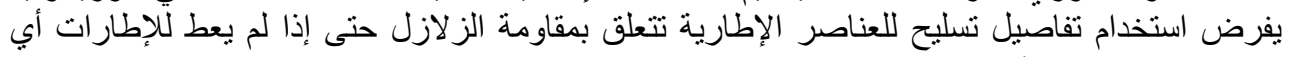

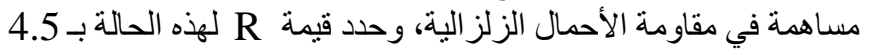




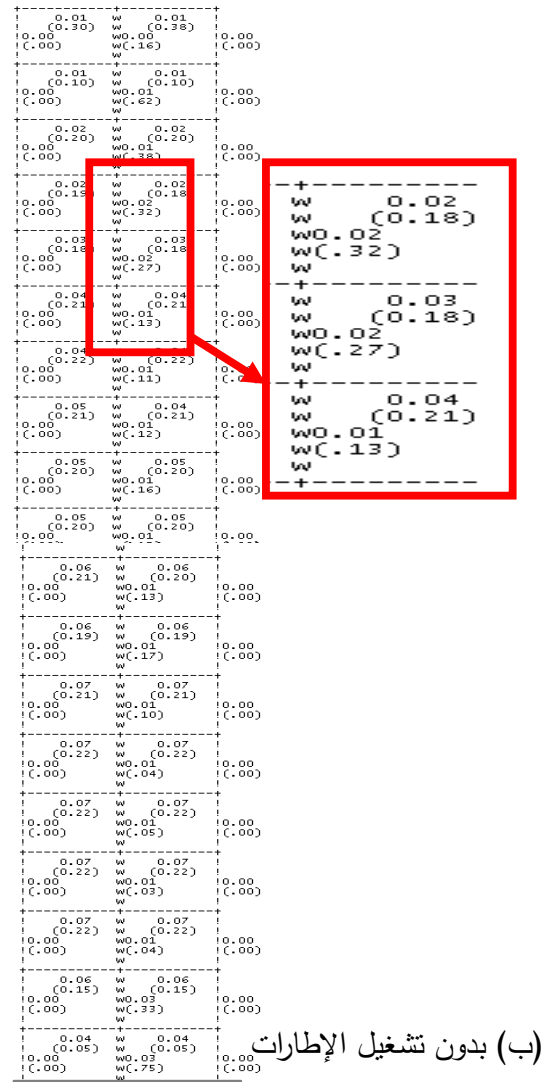

FW

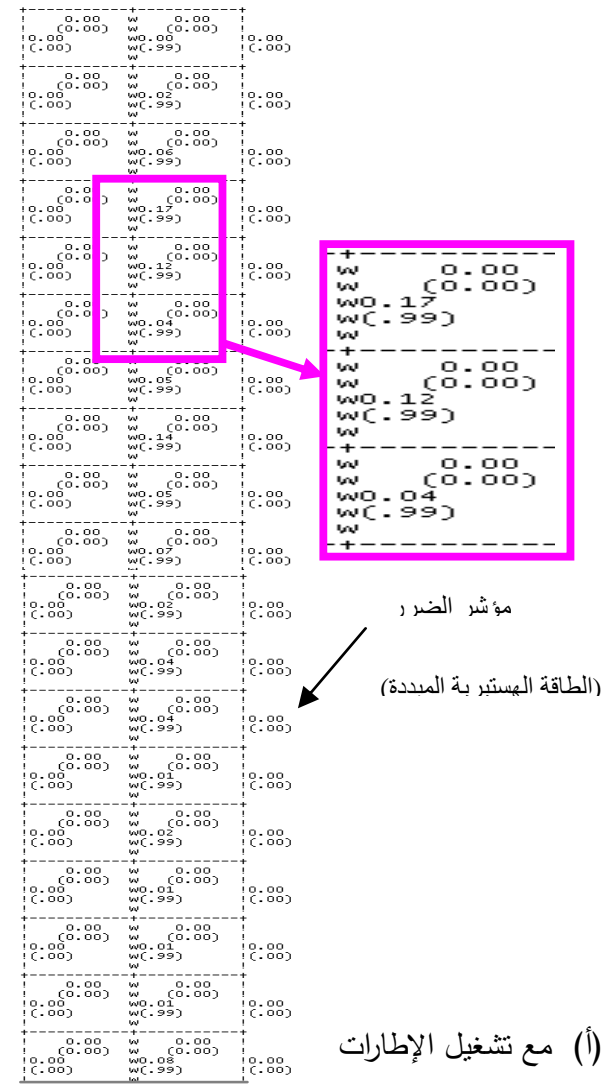

FW

الشكل(21): قيم مؤشر ات الضرر ومقدار الطاقة الهستيرية المبددة من خلال العناصر الإنشائية

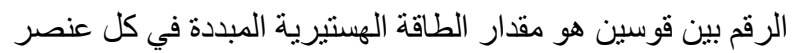

\section{9. نتائج وتوصيات}

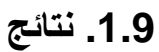

• إن عملية توزيع الأحمال الجانبية بين الإطار ات وحو ائط القص وفق صلابة كل منهما فقط تعتبر طريقة غير

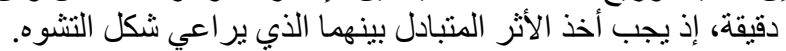

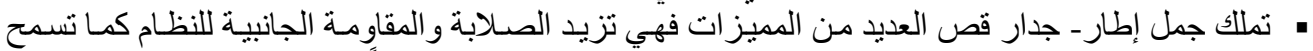

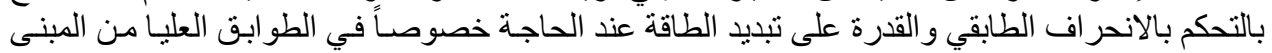
العنصربن.

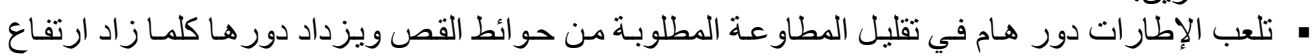

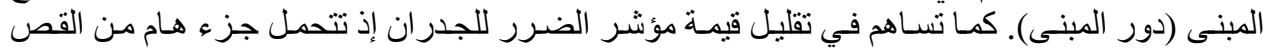
القاعدي حتى في المرحلة اللدنة.

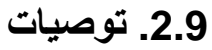

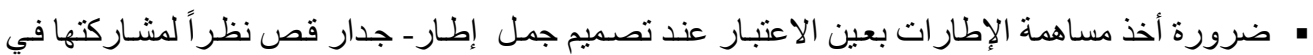

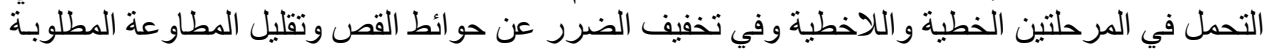

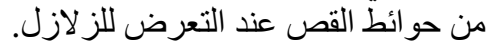
• تبني قيم R الواردة في الكود IBC2003 حيث أن هذا لا يتعارض مع بقاء العوامل الأخرى الواردة في للإل 


$$
\text { • وضع إجراءات لتصميم جمل إطار - جدار قص في الكود العربي السوري. }
$$$$
\text { [1] ] الكود العربي السوري لتصميم وتنفيذ الإنشاءات بالخرسانة المسلحة } 2005 \text { ، نقابة المهندسين. }
$$

[2]Khan، F. R. and Sbarounis، J.A.، "Interaction of Shear Walls and Frames in Concrete Structures under Lateral Loads،" Journal of the American Society of Civil Engineering، 90 (ST3)، June 1964.

[3] Iain A.، Macleod، Shear Wall-Frame Interaction - A Design Aid (EB066.01 D)، Portland Cement Association، 1970.

[4] Paullay، T. \& Priestly، M.J.N، Seismic Design of Reinforced Concrete and Massonary Building، 1995.

[5] Uniform Building Code (UBC) 1997، International Conference of Building Officials.

[6]International Building Code (IBC) 2003، International Code Council، INC.

[7]Valles، R. E. ' Reinhorn، A.M. Kunnath، S.K. and Madan‘ A Program for the Inelastic Damage Analysis of Buildings"، IDARC 2D Ver.6 Technical Report”، NCEER - State University of NewYork at Buffalo، 2005. 